This is the final peer-reviewed accepted manuscript of:

Alessandra Di Francesco, Marta Mari, Luisa Ugolini, Bruno Parisi, Jessica Genovese, Luca Lazzeri, Elena Baraldi

Reduction of acrylamide formation in fried potato chips by Aureobasidum pullulans L1 strain

which has been published in final form in International Journal of Food Microbiology

Volume 289, 16 January 2019, Pages 168-173

The final published version is available online at:

http://dx.doi.org/10.1016/j.ijfoodmicro.2018.09.018

(C) 2018 Elsevier. This manuscript version is made available under the Creative Commons Attribution-NonCommercial-NoDerivs (CC BY-NC-ND) 4.0 International License (http://creativecommons.org/licenses/by-nc-nd/4.0/) 


\title{
Reduction of acrylamide formation in fried potato chips by Aureobasidum pullulans L1 strain
}

\author{
Alessandra Di Francesco ${ }^{\mathrm{a}, \mathrm{b}}$, Marta Mari $^{\mathrm{a}}$, Luisa Ugolini ${ }^{\mathrm{c}}$, Bruno Parisi ${ }^{\mathrm{c}}$, Jessica Genovese ${ }^{\mathrm{d}}$, \\ Luca Lazzeri ${ }^{\mathrm{c}}$, Elena Baraldi ${ }^{\mathrm{a}, \mathrm{b}, *}$ \\ ${ }^{\text {a }}$ CRIOF - Department of Agricultural Sciences, University of Bologna, Via Gandolfi, 19, 40057 Cadriano, Bologna, Italy \\ b Department of Agricultural and Food Science, University of Bologna, Viale Fanin, 46, 40127 Bologna, Italy \\ ${ }^{\mathrm{c}}$ Council for Agricultural Research and Economics, Research Centre for Cereal and Industrial Crops (CREA-CI), Via di Corticella 133, 40128 Bologna, Italy \\ ${ }^{\mathrm{d}}$ Interdepartmental Centre for Agri-Food Industrial Research University of Bologna, Via Quinto Bucci 336, 47521 Cesena, Italy
}

\begin{abstract}
A B S T R A C T
Acrylamide is a potential carcinogenic molecule formed during food heat processing at high temperature (Maillard reaction). In the present study, the ability of the yeast Aureobasidium pullulans to deplete the acrylamide precursor free asparagine in fresh potatoes was investigated. A. pullulans applied before final frying changes the free amino acid composition of potatoes, decreasing the content of free asparagine by $16 \%$ and reducing acrylamide by $83 \%$ in fried potatoes. Potato browning was also reduced by yeast treatment without negative drawbacks on chip taste. This yeast, commonly used in fruit postharvest disease control, can therefore also be applied in potato and bakery industries to reduce food acrylamide content.
\end{abstract}

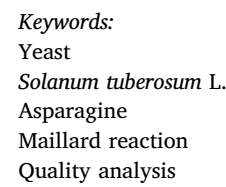

\section{Introduction}

Food products such as potato chips, French fries, bread or processed cereals, which are cooked at over $120^{\circ} \mathrm{C}$, accumulate acrylamide 'probably carcinogenic to humans' (Medeiros Vinci et al., 2012). Acrylamide reduction is at present considered one of the major challenges in the food industry. In order to decrease the acrylamide content, the EU commission has recently restricted the acrylamide level suggested for food commercialization (EU, 2017/2158) to 500 and $750 \mu \mathrm{g} / \mathrm{kg}$ (parts per billion) for French fries and potato chips, respectively. As is well known, the Maillard reaction is responsible for the formation of acrylamide in heated food (Halford et al., 2011). In potato, the relationship between precursor concentration and acrylamide formation is complex (Muttucumaru et al., 2017); reducing sugars and free asparagine are reported as the principal determinants of acrylamide formation but other free amino acids and food processing parameters and cooking conditions can also contribute to the reaction and increase the acrylamide level (Muttucumaru et al., 2013, 2014; Shepherd et al., 2010).

In potatoes, asparagine is usually the most abundant free amino acid (Muttucumaru et al., 2017) with a fairly narrow content range among different cultivars (Bethke and Bussan, 2013). Silencing of asparaginase genes in transgenic potatoes allowed a significant reduction in tuber acrylamide-formation, but led to small cracked potato tubers in open field (Chawla et al., 2012).

The total amount of free amino acids can also vary according to field management, water and nutrient availability, nitrogen fertilization and harvest timing (Muttucumaru et al., 2014, 2017). In fact, at present, in order to diminish acrylamide formation in potato chips, agronomic and storage practices are applied to reduce sugars and asparagine in tubers, such as the use of different cultivars and different storage temperatures, together with technical strategies such as dipping in additive solutions, reduction of thermal input or use of the asparaginase enzyme or yeast/ lactic bacteria (Anese et al., 2009; Elmore et al., 2015; Halford et al., 2012). Processing methods are also used to moderate acrylamide formation: blanching, $\mathrm{pH}$ reduction and the use of the asparaginase enzyme are the methods most used. Blanching is used to leach acrylamide precursors and to obtain a uniform colour after frying by means of a layer of gelatinized starch that limits oil absorption and improves texture (Haase et al., 2003; Samir et al., 2013).

Lowering the $\mathrm{pH}$ of the foodstuff would block the nucleophilic addition of asparagine with a carbonyl compound, preventing the formation of the corresponding Schiff base, a key intermediate in the Maillard reaction and formation of acrylamide (Mestdagh et al., 2008). Finally, the use of asparaginase enzyme can be considered, and industrial production of this enzyme is nowadays carried out mostly using

\footnotetext{
* Corresponding author at: CRIOF - Department of Agricultural Sciences, University of Bologna, Via Gandolfi, 19, 40057 Cadriano, Bologna, Italy. E-mail address: elena.baraldi@unibo.it (E. Baraldi).
} 
bacteria or fungi (Aiswarya and Baskar, 2018; Hendriksen et al., 2009). However, the enzymes produced by prokaryotes have some problems of hypersensitivity and immune inactivation (Narta et al., 2007), so eukaryotic microorganisms such as fungi (Krishnakumar and Visvanathan, 2014) and yeasts (Soler et al., 2015) have also been considered for Lasparaginase production (Muso Cachumba et al., 2016).

Aureobasidium pullulans L1 strain is a potential biocontrol agent active against different fruit postharvest pathogens, representing a promising alternative to common fungicides in the control of postharvest diseases (Di Francesco et al., 2016). Recently, we reported that the strain L1 has the ability to successfully assimilate peach juice free amino acids such as asparagine, making this nutrient unavailable to pathogens and allowing them to rapidly proliferate (Di Francesco et al., 2017). In light of these considerations, the present study was undertaken to explore the ability of the L1 strain to diminish the potato acrylamide content. The consumption of free amino acids, particularly asparagine, displayed by L1 yeast treatment was thus evaluated in potato homogenate and in potato slices before frying and acrylamide and quality parameters were then evaluated in the final fried potato chips.

\section{Materials and methods}

\subsection{Aureobasidium pullulans strain $L 1$}

Aureobasidium pullulans strain L1, previously identified by Mari et al. (2012) and molecularly characterized by Di Francesco et al. (2018a), was maintained on nutrient yeast dextrose agar (NYDA) consisting of nutrient broth $8 \mathrm{~g}$, yeast extract $5 \mathrm{~g}$, dextrose $10 \mathrm{~g}$ and technical agar $15 \mathrm{~g}$ (all from Oxoid, Basingstoke, UK) in $1 \mathrm{~L}$ of distilled water, and stored at $4{ }^{\circ} \mathrm{C}$ until use. Two days before the experiments, the yeast was cultured in $250 \mathrm{~mL}$ conical flasks containing $50 \mathrm{~mL}$ of nutrient yeast dextrose broth (NYDB: NYDA without agar) on a rotary shaker at $200 \mathrm{rpm}$ for $48 \mathrm{~h}$ at $25^{\circ} \mathrm{C}$. Washed cell suspension was prepared by centrifugation of the liquid culture samples at $6000 \mathrm{~g}$ for $10 \mathrm{~min}$ at $4{ }^{\circ} \mathrm{C}$, and then washed twice with sterile distilled water to remove the growth medium. The yeast was suspended in sterile distilled water and adjusted to an initial concentration of $1 \times 10^{8}$ cells $/ \mathrm{mL}$.

\subsection{Potato and analysis of reducing sugars}

Potato tubers (Solanum tuberosum cv "Primura") were obtained from the CREA experimental field located in Budrio (Bologna, Italy) and were harvested from plants at the senescence growth stage BBCH 97907 (leaves and stem dead, stems bleached and dry). At least 10 U.S. N.1 tubers $\left(5 \mathrm{~cm}\right.$ or $112 \mathrm{~g}$ minimum) of uniform shape were stored at $7{ }^{\circ} \mathrm{C}$ with $90 \%$ RH (relative humidity). For the experiment, potatoes were manually washed and peeled. The two ends of the potato were eliminated and slices $(2.0 \pm 0.3 \mathrm{~mm}$ thickness) were cut using an electric slicing machine (model HR7776/90, Philips, Amsterdam, the Netherlands). The reducing sugar content of the potatoes used in the described experiments was determined on freeze-dried samples by extracting with distilled water 1:50 $(\mathrm{w} / \mathrm{v})$. The aqueous suspension was first mixed by vortex for $8 \mathrm{~min}$ and further subjected to ultrasoundassisted extraction for $20 \mathrm{~min}$. After centrifugation $(30,500 \mathrm{~g}, 30 \mathrm{~min}$, $10{ }^{\circ} \mathrm{C}$ ), the supernatant was filtered on paper filter and diluted 1:2 with water. Sugar analysis was performed by HPLC using a Hewlett-Packard Model series 1100 system, coupled with an evaporative light scattering detector (SEDEX LT-ELSD Model 85LT SEDERE), a Shodex Sugar SP-G column and the corresponding guard column. Isocratic elution was performed at $80^{\circ} \mathrm{C}$ by water at a flow rate of $0.5 \mathrm{~mL} / \mathrm{min}$. $20 \mu \mathrm{L}$ of sample solution spiked with arabinose as internal standard were injected and sugar quantification was calculated from a previous determined calibration curve using pure standards.

\subsection{Qualitative method to detect L1 strain L-asparaginase activity}

Asparaginase enzyme activity was tested through a rapid plate assay (Saxena and Sinha, 1981) made by suspending glucose $2 \mathrm{~g}$, L-asparagine (Sigma Aldrich, Saint Louis, USA) $10 \mathrm{~g}, \mathrm{KH}_{2} \mathrm{PO}_{4} 1.52 \mathrm{~g}, \mathrm{KCl} 0.52 \mathrm{~g}$ and traces of $\mathrm{CuNO}_{3} \cdot 3 \mathrm{H}_{2} \mathrm{O}$ (trace), $\mathrm{ZnSO}_{4} \cdot 7 \mathrm{H}_{2} \mathrm{O}, \mathrm{FeSO}_{4} \cdot 7 \mathrm{H}_{2} \mathrm{O}$, agar technical $15 \mathrm{~g}$ in $1000 \mathrm{~mL}$ of distilled water. The medium was supplemented with $3 \mathrm{~mL}$ of a phenol red stock solution (2.5\%) dissolved in ethanol (pH 6.2). Plates were inoculated with a yeast plug ( $5 \mathrm{~mm}$ diameter) cut from a $48 \mathrm{~h}$ colony and incubated at $25^{\circ} \mathrm{C}$. Control plates consisted of the medium without yeast plug. After 7 days of incubation, the agar shading to pink colour was verified. At least 30 plates of treated or control samples were analyzed. The assay was repeated once.

\subsection{Pre-frying treatments}

Treatments with L1 strain were performed on raw sliced potatoes in order to evaluate their effect on free asparagine reduction and acrylamide formation after frying. Sliced potatoes, two replicates of 40 slices each (from at least 20 different tubers) homogeneous in size, were immediately rinsed in distilled water for a few seconds to eliminate starch material on the surface and dipped in $250 \mathrm{~mL}(1: 2 \mathrm{w} / \mathrm{v})$ of $\mathrm{L} 1$ suspension $\left(1 \times 10^{8}\right.$ cells $\left./ \mathrm{mL}\right)$ for $30 \mathrm{~min}$ at $25^{\circ} \mathrm{C}$. As a control, potato slices were rinsed and immersed in distilled water under the same conditions. At the end of the treatments, potatoes were quickly rinsed again in distilled water, dried with absorbent paper, and deep-fried in $2 \mathrm{~L}$ of vegetable oil (high oleic sunflower oil) at $180^{\circ} \mathrm{C} \pm 3^{\circ} \mathrm{C}$ for $150 \mathrm{~s}$, by using a thermo stable electrical fryer (Deep Fryer, De Longhi, Italy) with a static basket. The frying was repeated once.

After frying, potato slices were drained to remove oil excess and subjected to $\mathrm{pH}$, colour and acrylamide analyses. Before frying, samples of raw potatoes, treated and control, were collected for HPLC free amino acid analysis.

\subsection{Preliminary evaluation of yeast free asparagine consumption in potato homogenate and potato slices by free amino acid HPLC analysis}

Raw potatoes were homogenized by using a mixer (Imetec Ch4, Italy) and samples of the obtained potato homogenate $(1 \mathrm{~g})$ were incubated for $30 \mathrm{~min}$ at $25^{\circ} \mathrm{C}$ with 1 or $2 \mathrm{~mL}(1: 1$ or $1: 2 \mathrm{w} / \mathrm{v})$ of L1 suspension $(1 \times 108$ cells $/ \mathrm{mL})$ or distilled water (control). Control and yeast-treated suspension after incubation were extracted for free amino acid analysis by first diluting up to $1: 5(\mathrm{p} / \mathrm{v})$ with water and then by $30 \mathrm{~s}$ of vortex agitation followed by $10 \mathrm{~s}$ of sonication. The final extracts were centrifuged at $16,000 \mathrm{~g}$ for $20 \mathrm{~min}$ at $4{ }^{\circ} \mathrm{C}$, micro-filtered (Millex sterile syringe filter $0.22 \mu \mathrm{m}$, Merck, Germany) for yeast elimination, and analyzed by HPLC for free amino acid detection as described below. Three independent biological replicates of each treated and control sample were prepared, pulled together and analyzed. The analysis was repeated once.

For free amino acid determination, $5 \mathrm{~g}$ of sliced potatoes were extracted in $50 \mathrm{~mL}$ of $\mathrm{H}_{2} \mathrm{O}$ for $4 \mathrm{~min}$ by using a lab blender at room temperature; the suspension was then sonicated for $10 \mathrm{~min}$ and finally centrifuged $(31,500 \mathrm{~g}$ for $30 \mathrm{~min})$, micro-filtered $(0.22 \mu \mathrm{m})$ and diluted with $0.1 \mathrm{M}$ hydrochloric acid ( $\mathrm{HCl}$ ) if necessary before HPLC analysis. Free amino acids were determined by reversed phase HPLC analysis and automated pre-column derivatisation with o-phtalaldehyde-3-mercaptopropionic acid (OPA) for primary and 9-fluorenylmethylchloroformate (FMOC) for secondary amino acids, according to Agilent procedures (Application note 5990-4547EN 2010), with some modifications. A Hewlett-Packard Model series 1100 system, coupled with a diode array detector (UV wavelength set at 338 and $262 \mathrm{~nm}$ ), a Gemini C18 column ( $110 \AA-4.6 \times 250 \mathrm{~mm}, 5 \mu \mathrm{m}$ Phenomenex) and the corresponding guard column were used. Chromatographic conditions are described in Di Francesco et al. (2018b). Quantitative analysis was performed by using norvaline and sarcosine as internal standards for 
primary and secondary free amino acids, respectively. Single peak response factors for twenty-one free amino acids relative to internal standard were calculated as the ratio between calibration curve slopes of each free amino acid standard and the internal standard. Calibration curves were constructed from amino acid standard solutions in $0.1 \mathrm{~N}$ $\mathrm{HCl}$, prepared following Agilent procedures. The analytical limited of quantification was determined for each amino acid $(0.07-0.30 \mathrm{~g} / \mathrm{kg})$. Samples of potato extracts were injected before dilution with $0.1 \mathrm{~N} \mathrm{HCl}$ when necessary and analyses were replicated three times.

\subsection{Quality analysis after frying: colour, texture, oil content and $\mathrm{pH}$ measurements of potato chips}

Colour analyses were conducted with a tristimulus colorimeter (Chromameter-3-Reflectance, Minolta, Osaka, Japan) equipped with a CR-200 measuring head and attached to a data processor DP-100. The colour was recorded using the CIE (Commission Internationale d'Eclairage) colour scale, parameters of $\mathrm{L}^{*}$ (whiteness/darkness), a* (redness/greenness), and $\mathrm{b}^{*}$ (yellowness/blueness). The instrument calibration was conducted using a white standard tile $\left(\mathrm{L}^{*}=98.03\right.$, $\left.a^{*}=-0.23, b^{*}=2.05\right)$ before the measurements. Hue angle $\left(h^{\circ}\right)$, which is the hue in the CIELAB colour space, was calculated by the following equation:

$\mathrm{h}^{\circ}=\tan ^{-1} \mathrm{~b}^{*} / \mathrm{a}^{*}$

The readings were carried out on both sides of the fried chips, twenty for each treatment, and the mean value was defined. Potato chip texture measurement was performed at room temperature $\left(23 \pm 2{ }^{\circ} \mathrm{C}\right)$ after frying, using a Texture Analyzer mod. TA-HDi (Stable Micro Systems, Surrey, UK), equipped with a $50 \mathrm{~kg}$ load cell and a stain less steel $4 \mathrm{~mm}$ spherical probe (HDP/CFS) at $5 \mathrm{~mm} / \mathrm{min}$ test speed. The parameter used to describe the texture of the samples was hardness, defined as the peak force observed at the maximum compression (Steffe, 1996). For each sample, 20 potato slices were measured. Total oil content was determined by solvent extraction using the Soxhlet method (AACC, 1986), performing the extraction procedure with petroleum ether. Oil content was reported as a percentage on a moisturefree basis. The $\mathrm{pH}$ measurements were carried out using a $\mathrm{pH}$ meter (Crison pH $25+$, Barcelona, Spain), homogenizing and measuring $10 \mathrm{~g}$ of potato chips for each treatment.

\subsection{Acrylamide determination}

An amount of $400 \mathrm{ng}$ of isotopic labelled acrylamide dissolved in water was added to $2 \mathrm{~g}$ of test sample followed by ethyl acetate in an equal volume $(1: 1 \mathrm{v} / \mathrm{v})$. The suspension was shaken to extract the fat from the sample, then cold water $(20 \mathrm{~mL})$ was added and the mixture was placed on a mechanical shaker for a further $15 \mathrm{~min}$. After centrifugation $(3000 \mathrm{~g}, 5 \mathrm{~min})$, a $10 \mathrm{~mL}$ aliquot of the aqueous phase was transferred to a glass vial and derivatised by adding $15 \mathrm{~mL}$ of a mixture of potassium bromide, hydrobromic acid and saturated bromine water. Bromination took place in the dark at $4{ }^{\circ} \mathrm{C}$, within $1 \mathrm{~h}$. Excessive derivatisation reagent was decomposed by adding a few drops of an aqueous sodium thiosulphate solution. The resulting 2,3-dibromopropanamide was extracted with $8 \mathrm{~mL}$ of ethyl acetate. Half of that volume was pipetted into a clean glass vial, dried over anhydrous, granular sodium sulphate; the dried extract was then transferred into another clean vial and evaporated under a stream of nitrogen to a volume below $0.5 \mathrm{~mL}$. To avoid uncontrolled dehydro-bromination in the hot injector of the GC, $50 \mu \mathrm{L}$ of triethylamine was added in order to deliberately dehydro-brominate the analyte. Finally, 2-bromopropenamide was analyzed by GC-MS (Agilent 7890A) on a GC column DBWAX ( $30 \mathrm{~mm}-\emptyset 250 \mu \mathrm{m}-0.25 \mu \mathrm{m})$. The mass spectrometer was run in selected ion monitoring mode. The monitored mass charge ratios are 149, 151 and 152 for the ${ }^{13} \mathrm{C}$ labelled internal standard (Castle and Eriksson, 2005). Neotron Lab Service (Modena, Italy) conducted the analysis.

\subsection{Statistical analysis}

Data were subjected to a one-way analysis of variance (ANOVA). Separation of means was performed using the least significant difference (LDS) test, at $p<0.05$. Data are reported as mean values \pm standard error (SE) of independent experiments. All experiments were carried out in a completely randomized design. All analyses were performed with the software Statgraphic Plus Version 2.1 (Statistical Graphics Corp., USA 1996).

\section{Results}

\subsection{L1 strain L-asparaginase activity}

In order to verify the presence of asparaginase activity on the ground potatoes, a plate assay screening was performed. Here a phenol red $\mathrm{pH}$ indicator was added to the culture medium to reveal the $\mathrm{pH}$ alteration induced by the release of ammonia ions by the L-asparaginase activity. Phenol red is yellow at acid $\mathrm{pH}$ and turns pink at alkaline $\mathrm{pH}$, thus the production of L-asparaginase by the L1 yeast appears as a pink halo around the yeast colony. By culturing L1 on the phenol red screening plate amended with asparagine amino acid, a visible pink colour was detected on the plate after seven days around the colony growth (Fig. 1A). The halo was due to the yeast enzyme activity since no halo was detected on the control plate, without the yeast colony (Fig. 1B).

\subsection{Potato sugar content, free amino acid consumption by L1 strain in potato homogenate and pre-treatment raw sliced potatoes}

From sugar analysis performed with HPLC, potatoes (NT) used in the present work displayed a reducing sugar content of $40 \mathrm{~g} / \mathrm{kg}$ (DW).

The free amino acid metabolism of the yeast L1 was first evaluated in a potato homogenate as a model system which allowed extensive contact between the yeast suspension and the potato proteins/amino acids. Incubation of the potato homogenate with the L1 suspension for $30 \mathrm{~min}$ at $25^{\circ} \mathrm{C}$ determined a consumption of free asparagine from $3.60 \mathrm{~g} / \mathrm{kg}$ (DM, dry matter) in the water treated sample (control sample), reaching an undetectable level in $30 \mathrm{~min}$ at $25^{\circ} \mathrm{C}$ (asparagine limit of detection $0.11 \mathrm{~g} / \mathrm{kg}$ ), with both a $1: 1$ and a $1: 2(\mathrm{w} / \mathrm{v})$ ratio of potato to aqueous solution. This was probably due to the yeast asparaginase enzyme activity, which hydrolyzes asparagine to aspartic acid releasing ammonia, as suggested by the increased concentration of aspartic acid in treated potatoes about two and a half times higher than the control (from $2.16 \mathrm{~g} / \mathrm{kg}$ to $5.30 \mathrm{~g} / \mathrm{kg} \mathrm{DM}$ ). The content of the other free amino acids was very low and no significant changes were found
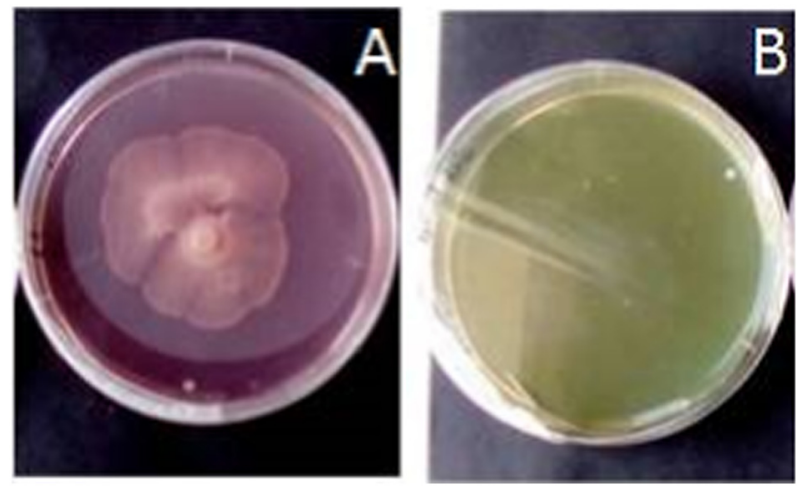

Fig. 1. L-asparaginase screening assay. (A) Agar plate inoculated with the L1 yeast; (B) control plate without microorganism inoculation, after 7 days of incubation at $25^{\circ} \mathrm{C}$. 
Table 1

Free amino acids (AA) content $(\mathrm{g} / \mathrm{kg})$ in sliced potato samples not subjected to treatment (NT), dipped in distilled water (CTRL) and in L1 suspension (108 cell/mL) (L1) $(1: 2 \mathrm{w} / \mathrm{v})$ for $30 \mathrm{~min}$ at $25^{\circ} \mathrm{C}$. AA decrease of CTRL vs NT samples and L1 vs CTRL samples, is reported as \% (AA \% decrease). Results are expressed on dry matter basis. NT, CTRL and L1 samples means followed by the same letters in the same raw are not statistically different ( $p<0.05$, LSD test).

\begin{tabular}{llllll}
\hline & NT & CTRL & $\begin{array}{l}\text { AA\% } \\
\text { decrease } \\
\text { CTRL } v \text { NT }\end{array}$ & L1 & $\begin{array}{l}\text { AA \% } \\
\text { decrease } \\
\text { L1 vs CTRL }\end{array}$ \\
\hline Aspartic acid & $1.63 \mathrm{a}$ & $1.04 \mathrm{~b}$ & 36.2 & $0.92 \mathrm{~b}$ & 11.5 \\
Glutammic acid & $2.12 \mathrm{a}$ & $1.65 \mathrm{~b}$ & 22.2 & $1.37 \mathrm{c}$ & 17.0 \\
Asparagine & $6.49 \mathrm{a}$ & $5.45 \mathrm{~b}$ & 16.0 & $4.57 \mathrm{c}$ & 16.1 \\
Serine & $1.14 \mathrm{a}$ & $0.69 \mathrm{~b}$ & 39.5 & $0.57 \mathrm{c}$ & 17.4 \\
Glutamine & $7.83 \mathrm{a}$ & $6.66 \mathrm{~b}$ & 14.9 & $5.69 \mathrm{c}$ & 14.6 \\
Threonine & $1.14 \mathrm{a}$ & $0.92 \mathrm{~b}$ & 19.3 & $0.74 \mathrm{c}$ & 19.6 \\
Arginine & $1.10 \mathrm{a}$ & $1.13 \mathrm{a}$ & -2.7 & $0.73 \mathrm{~b}$ & 35.4 \\
Alanine & $0.37 \mathrm{a}$ & $0.33 \mathrm{~b}$ & 10.8 & $<0.07^{*} \mathrm{c}$ & $>78.8$ \\
Tyrosine & $0.92 \mathrm{a}$ & $0.79 \mathrm{a}$ & 14.1 & $<0.17^{*} \mathrm{~b}$ & $>78.5$ \\
Valine & $1.77 \mathrm{a}$ & $1.40 \mathrm{~b}$ & 20.9 & $1.02 \mathrm{c}$ & 27.1 \\
Methionine & $0.59 \mathrm{NS}$ & $0.71 \mathrm{NS}$ & $\mathrm{NS}$ & $0.24 \mathrm{NS}$ & $\mathrm{NS}$ \\
Phenylalanine & $1.05 \mathrm{a}$ & $0.86 \mathrm{a}$ & 18.1 & $0.30 \mathrm{~b}$ & 65.1 \\
Isoleucine & $0.71 \mathrm{a}$ & $0.70 \mathrm{a}$ & 1.4 & $0.22 \mathrm{~b}$ & 68.6 \\
Leucine & $0.37 \mathrm{NS}$ & $0.32 \mathrm{NS}$ & $\mathrm{NS}$ & $<0.10^{*} \mathrm{NS}$ & $\mathrm{NS}$ \\
Tot & $27.23 \mathrm{a}$ & $22.65 \mathrm{~b}$ & 16.8 & $16.71 \mathrm{c}$ & 26.2 \\
\hline
\end{tabular}

NS = not significant difference between samples.

* The reported value indicates the AA analysis limit of quantification.

(data not shown). The L1 consumption of free asparagine and other amino acids was therefore verified by applying a treatment process to sliced potatoes closer to an industrial approach, as reported in Table 1.

Potatoes were processed for fried chip production by following a protocol as similar as possible to industrial processing. A treatment step of raw sliced potatoes with L1 yeast suspension $\left(1 \times 10^{8}\right.$ cell $\left./ \mathrm{mL}\right)$ before frying was conducted in order to reduce acrylamide formation and was compared with a control test where sliced potatoes had been immersed in water under the same conditions. The amino acid analysis was performed on sliced potato samples, not subjected to any treatment, and on potatoes treated with L1 suspension or only distilled water $(1: 2 \mathrm{w} / \mathrm{v})$ for $30 \mathrm{~min}$ at $25^{\circ} \mathrm{C}$, before frying.

Among the 21 amino acids, only 14 were detected, since histidine, glycine, cystine, tryptophane, lysine, hydroxyl-proline and proline were below the detectable values (Table 1).

In raw non-treated (NT) potato samples, free asparagine was the second most abundant amino acid, after glutamine, with concentrations of $6.49 \mathrm{~g} / \mathrm{kg}$ and $7.83 \mathrm{~g} / \mathrm{kg}(\mathrm{DM})$, respectively, corresponding to approximately $24 \%$ and $29 \%$ of total free amino acids. This is in accordance with the mean values found in the literature for various Italian varieties (Marchettini et al., 2013), even if their potato amino acids content varied depending on factors like variety, location, fertilization, storage and processing type (Martin and Ames, 2001). Free aspartic and glutamic acid, serine, threonine, arginine, valine and phenylalanine were also well represented free amino acids, with concentrations ranging from 1.05 to $2.12 \mathrm{~g} / \mathrm{kg}$.

Both the water-treated control sample (CTRL) and the yeast suspension treated one (L1) presented a modified free amino acid composition. In particular, water immersion for $30 \mathrm{~min}$ at $25^{\circ} \mathrm{C}$ determined a decrease of $16.8 \%$ of total free amino acids, greater for serine, aspartic acid, glutamic acid and valine (20-40\%). Free asparagine content also decreased by $16 \%$ if compared to the untreated potatoes (NT). The treatment with the yeast under the same conditions (L1) determined an additional decrease of $26 \%$ of total free amino acids compared to the control water treated samples. This decrease was particularly pronounced for free alanine, tyrosine, phenyl alanine and isoleucine $(70 \%-80 \%)$, the concentrations of which were close to the analytical detection limit in the final samples. Free arginine content also greatly decreased by $35 \%$ and free asparagine loss was $16 \%$ with respect to the control.

\subsection{Acrylamide content, colour evaluation, texture, oil and $\mathrm{pH}$ of potato chips}

The effect of L1 yeast treatment on the acrylamide content of potatochips, which is normally generated by asparagine and sugar through the Maillard reaction during high temperature treatment, was evaluated to explore the possible application of the L1 strain at industrial level.

Under visual analysis, frying determined a strong colour, turning the control potatoes brown, whereas treated L1 potato chips appeared much lighter in colour (Fig. 2). This colour difference was confirmed by the higher value of lightness $\mathrm{L}^{*}$ and hue angle colour parameters in L1 samples (Table 2). Texture values were also higher in the L1 samples while no statistical difference was detected between the control and treated potato chips' dry weight values (data not shown). The oil uptake after frying in both control and treated potato chips did not show significant differences either.

The $\mathrm{pH}$ values of control and treated fried potatoes were also evaluated in order to highlight possible flavour alterations. Unlike other processes aiming at reducing acrylamide, such as lactic acid fermentation (Baardseth et al., 2006), pre-treatment with L1 yeast did not determine changes in the $\mathrm{pH}$ values.

Instead, a drastic decrease of acrylamide content in treated fried chips was indeed demonstrated by GC-MS analysis, where only $260 \mu \mathrm{g} /$ $\mathrm{kg}( \pm 31)$ of acrylamide was detected in treated chips, corresponding to a $>83 \%$ reduction compared to the control $(1600 \mu \mathrm{g} / \mathrm{kg})( \pm 53)$ (Fig. 3), achieving a significant $(p<0.05$, LSD) reduction in mean acrylamide.

\section{Discussion}

Aureobasidium pullulans L1 strain was originally identified and characterized as a Bio Control Agent (BCA) of postharvest fruit diseases (Di Francesco et al., 2018a). Its ability to reduce acrylamide content in potato chips was investigated here on the basis of our previous studies (Di Francesco et al., 2017). The asparaginase activity exerted by L1 was firstly assessed by evaluating the release of ammonia ions on plate assay screening. This is a qualitative screening of the L1 enzyme activity based on substrate colour changing, commonly used to test

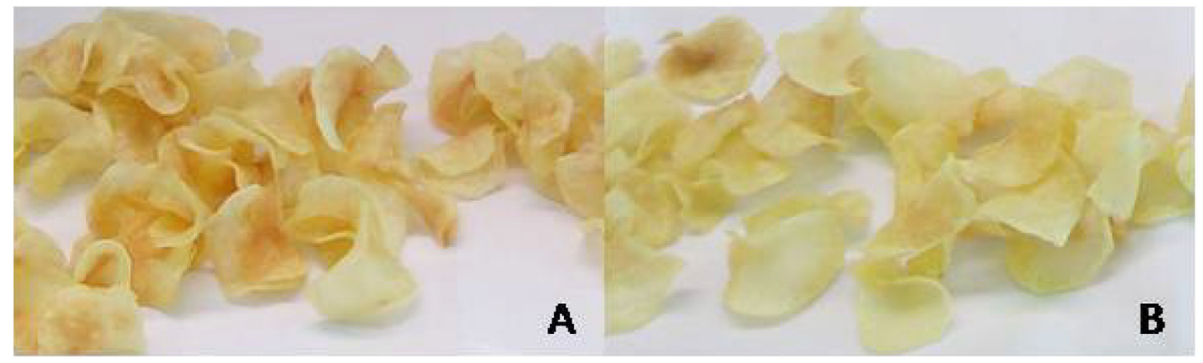

Fig. 2. Potato chips treated before frying A) with distilled water and B) L1 suspension $\left(1 \times 10^{8}\right.$ cells $\left./ \mathrm{mL}\right)$. 
Table 2

Colour, texture, oil content and $\mathrm{pH}$ values of potato chips samples after frying.

\begin{tabular}{|c|c|c|c|c|c|}
\hline Treatment & Lightness $\left(\mathrm{L}^{*}\right)$ & Hue angle $\left(\tan ^{-1} b^{*} / a^{*}\right)$ & Texture (crispness, N) & Oil content (\%) & $\mathrm{pH}$ \\
\hline CTRL & $57.22 \pm 4.88 \mathrm{a}$ & $83.27 \pm 3.0 \mathrm{a}$ & $2.57 \pm 0.8 \mathrm{a}$ & $40.64 \pm 0.13 a$ & $6.4 \pm 0.4 a$ \\
\hline L1 & $59.09 \pm 3.00 \mathrm{~b}$ & $85.15 \pm 4.0 \mathrm{~b}$ & $2.90 \pm 0.6 \mathrm{~b}$ & $41.30 \pm 1.04 a$ & $6.6 \pm 0.3 a$ \\
\hline
\end{tabular}

CTRL and L1 samples means followed by the same letters in the same raw are not statistically different ( $p<0.05$, LSD test).

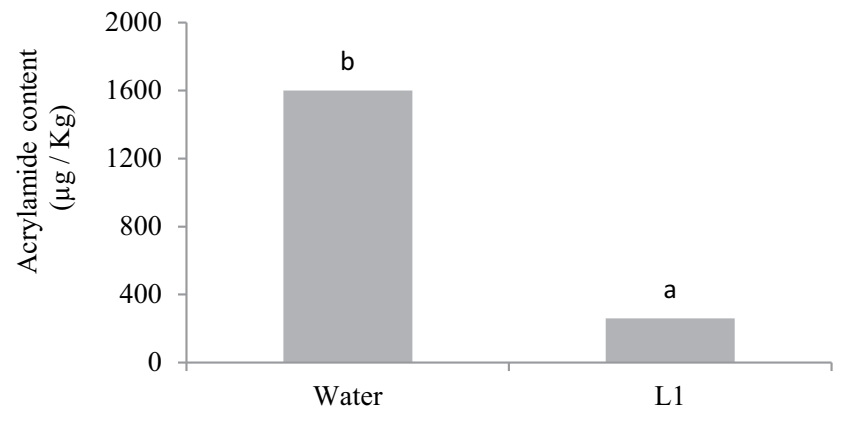

Fig. 3. Acrylamide content of fried potato chips.

After dipping with water and yeast strain L1 suspension $\left(1 \times 10^{8}\right.$ cells $\left./ \mathrm{mL}\right)$ for $30 \mathrm{~min}$ at $25^{\circ} \mathrm{C}$.

Water control and treatment with L1 strain followed by the same letters are not statistically different ( $p<0.05$, LSD test).

microorganisms' L-asparaginase activity in vitro (Mahajan et al., 2013; Saxena and Sinha, 1981).

When tested on potatoes before frying, L1 yeast causes a significant decrease in most of the potato detectable free amino acids, with a decrease of $26 \%$ of total free amino acids. This corresponded to $>10 \%$ of the free amino acid consumption found by treating potatoes with the basic mechanism of dipping in normal water, which by itself determined a reduction of almost $17 \%$ in total free amino acids. The two treatments together led to almost total depletion of these compounds in the final product, when compared to the untreated control sample.

When raw potato slices were pre-treated, before frying, by dipping in water at $25{ }^{\circ} \mathrm{C}$, a significant reduction of $26 \%$ of total free amino acids was detected, caused by their leaching-out in the aqueous medium.

In fried potato chips, pre-treatment with $\mathrm{L} 1$ determined a strong reduction (85\%) of acrylamide formation and a difference in colour with respect to the control, clearly indicating a significant reduction in the Maillard browning reaction in L1 potato samples. Acrylamide level is in fact positively correlated with colour (redness component $\mathrm{a}^{*}$ ) in fried potato slices during frying (Pedreschi et al., 2005a).

The yeast treatment effect could be ascribed to the asparagine consumption on the potato slice surface, which was more evident when the yeast cells were in extensive contact with potato homogenate with respect to the slice surface. This is probably due also to the easier leaching-out of solutes from potato homogenate. Nevertheless, other mechanisms could be involved in acrylamide mitigation of L1 treated potato slices, such as the modification of free amino acids other than asparagine, e.g. alanine, arginine, phenylalanine, and serine, which could also contribute to acrylamide production (Baardseth et al., 2006). Claeys et al. (2005), in fact, showed how the rate of acrylamide formation/elimination in a model system was influenced for instance by the presence of free glutamine, another basic amino acid involved in the Maillard reaction, suggesting that a mix of components play roles in acrylamide formation. On the other hand, recent studies speculated that free asparagine concentration could be a determinant for the variance in acrylamide-forming potential when its concentration is relatively low compared to the concentration of reducing sugars; a tipping point of about 2.260 in the ratio between free asparagine and reducing sugars was identified, above and below which reducing sugars or free asparagine are respectively the main limiting factor for acrylamide formation (Muttucumaru et al., 2017). Probably due to the long storage time (Zhou et al., 2015), the potato used in the present work had a high reducing sugar content $(40 \mathrm{~g} / \mathrm{kg}$ ) compared to asparagine (ratio asn/ reducing sugars $=0.221$ ), thus indicating that measurements were performed in a strongly limiting concentration of asparagine, and that free asparagine was by far the most important determinant factor in acrylamide formation (Granvogl et al., 2004). At industrial level, acrylamide reduction in potato chips could be achieved through treatment with L-asparaginase (Hendriksen et al., 2009; Kukurová et al., 2009; Pedreschi et al., 2011), which normally follows a blanching treatment where potatoes slices are quickly treated in hot water at $85^{\circ} \mathrm{C}$ for $3.5 \mathrm{~min}$ to reduce free sugars and free amino acids (Pedreschi et al., 2005b). The synergistic combination of blanching and the enzyme Lasparaginase treatment, where heat improves the free amino acid and sugar diffusion towards the enzyme solution, was in fact previously demonstrated (Pedreschi et al., 2008).

However, this process is expensive, requiring the use of dedicated machinery and large amounts of recombinant asparaginase enzymes (Furlan Goncarles Dias et al., 2017). Microorganisms with L-asparaginase activity have thus always attracted attention for innovative biotechnological applications, such as the extracellular asparaginase from an endophytic bacteria Pseudomonas oryzihabitans (Baghat et al., 2016) isolated from Hibiscus rosa-sinensis that produced a maximal level of asparaginase enzyme $(2.1 \mathrm{U} / \mathrm{mL})$, or the asparaginases produced by a strain of Paenibacillus barengoltzii that significantly decreased the acrylamide content in potato chips by $86 \%$ (Shi et al., 2017). The data presented here show how the L1 strain could be a valuable and sustainable means of preventing acrylamide formation in fried potatoes at industrial level without altering quality parameters such as oil content, texture and sensorial characteristics (Table 2). Yeast is a natural organism and can be easily and cheaply cultivated on a large scale, its application thus being economical and environmentally sustainable. Furthermore, the asparaginase activity of A. pullulans strain can also be of considerable interest for other food industry sectors, such as bakery or coffee production, where acrylamide represents a major problem, or for applications other than food processing. For over four decades Lasparaginase has been used as an antitumor and chemotherapeutic agent (Batool et al., 2015; Karamitros et al., 2013). The broad range of uses (Vimal and Kumar, 2017) where L-asparaginase is applied opens new possibilities of L1 applications that can be explored in future studies. In conclusion, the application of the A. pullulans L1 strain as a prefrying treatment of potato slices could represent an innovative and effective method for mitigating acrylamide formation in potato chips. An in-depth study on the A. pullulans L1 strain L-asparaginase enzyme and of the factors possibly influencing its activity is therefore needed, in order to better explain the yeast's efficacy and understand its mechanism of action to optimize its application.

\section{Acknowledgment}

This study was developed on the base of the patent $n$. 102017000105265 "Ceppo di lievito utilizzabile per ridurre la quantità di acrilammide in un alimento trattato termicamente". (Authors: Marta Mari, Alessandra Di Francesco and Luisa Ugolini; Alma Mater StudiorumBologna and CREA) (20.09.2017). 


\section{References}

AACC, 1986. Approved Methods of the American Association of Cereal Chemists. (Minneapolis).

Aiswarya, R., Baskar, G., 2018. Enzymatic mitigation of acrylamide in fried potato chips using asparaginase from Aspergillus terreus. Int. J. Food Sci. Technol. 53, 491-498.

Anese, M., Suman, M., Nicoli, M.C., 2009. Technological strategies to reduce acrylamide levels in heated foods. Food Eng. Rev. 1, 169-179.

Baardseth, P., Blom, H., Skrede, G., Mydland, T.L., Skrede, A., Slinde, E., 2006. Lactic acid fermentation reduces acrylamide formation and other Maillard reactions in French fries. J. Food Sci. 71, 28-33.

Baghat, J., Kaur, A., Chandha, B.S., 2016. Single step purification of asparaginase from endophytic bacteria Pseudomonas oryzihabitans exhibiting high potential to reduce acrylamide in processed potatochips. Food Bioprod. Process. 99, 222-230.

Batool, T., Makky, E.A., Jalal, M., Yusoff, M.M., 2015. A comprehensive review on Lasparaginase and its applications. Appl. Biochem. Biotechnol. 178, 900-923.

Bethke, P.C., Bussan, A.J., 2013. Acrylamide in processed potato products. Am. J. Potato Res. 90, 403-424.

Castle, L., Eriksson, S., 2005. Analytical methods used to measure acrylamide concentrations in foods. J. AOAC Int. 88, 274-284.

Chawla, R., Shakya, R., Rommens, C.M., 2012. Tuber-specific silencing of asparagine synthetase-1 reduces the acrylamide-forming potential of potatoes grown in the field without affecting tuber shape and yield. Plant Biotechnol. J. 10, 913-924.

Claeys, W.L., De Vleeschouwer, K., Hendricks, M.E., 2005. Effect of amino acids on acrylamide formation and elimination kinetics. Biotechnol. Prog. 21, 1525-1530.

Di Francesco, A., Martini, C., Mari, M., 2016. Biological control of postharvest diseases by microbial antagonists: how many mechanisms of action? Eur. J. Plant Pathol. 145, 711-717.

Di Francesco, A., Ugolini, L., D'Aquino, S., Pagnotta, E., Mari, M., 2017. Biocontrol of Monilinia laxa by Aureobasidium pullulans strains: insights on competition for nutrients and space. Int. J. Food Microbiol. 248, 32-38.

Di Francesco, A., Calassanzio, M., Ratti, C., Mari, M., Folchi, A., Baraldi, E., 2018a. Molecular characterization of the two postharvest biological control agents Aureobasidium pullulans L1 and L8. Biol. Control 123, 53-59.

Di Francesco, A., Mari, M., Ugolini, L., Baraldi, E., 2018b. Effect of Aureobasidium pullulans strains against Botrytis cinerea on kiwifruit during storage and on fruit nutritional composition. Food Microbiol. 72, 67-72.

Elmore, J.S., Briddon, A., Dodson, A.T., Muttucumaru, N., Halford, N.G., Mottram, D. 2015. Acrylamide in potato crisps prepared from 20 UK-grown varieties: effects 510 of variety and tuber storage time. Food Chem. 182, 1-8.

EU, 2017/2158. https://eur-lex.europa.eu/eli/reg/2017/2158/oj.

Furlan Goncarles Dias, F., Bogusz Junior, S., Hantao, L., Augusto, F., Sato, H., 2017. Acrylamide mitigation in French fries using native L-asparaginase from Aspergillus oryzae CCT 3940. LWT Food Sci. Technol. 76, 222-229.

Granvogl, M., Juzussek, M., Koehler, P., Schieberle, P., 2004. Quantitation of 3-aminopropionamide in potatoes - a minor but potent precursor in acrylamide formation. $\mathrm{J}$. Agric. Food Chem. 52, 4751-4757.

Haase, N.U., Matthäus, B., Vosmann, K., 2003. Minimierun gansätzezur acrylamid-bildung in pflanzlichen lebensmittel naufgezeigtambeispiel von kartoffelchips. Dtsch. Lebensmitt. Rundsch. 99, 87-90.

Halford, N.G., Curtis, T.Y., Muttucumaru, N., Postles, J., Mottram, D.S., 2011. Sugars in crop plants. Ann. Appl. Biol. 158, 1-25.

Halford, N.G., Muttucumaru, N., Powers, S., Gillatt, P.N., Hartley, S., Elmore, J.S., Mottram, D.S., 2012. Concentrations of free amino acids and sugars in nine potato varieties: effects of storage and relationship with acrylamide formation. J. Agric. Food Chem. 60, 12044-12055.

Hendriksen, H.V., Kornbrust, B.A., Østergaard, P.R., Stringer, M.A., 2009. Evaluating the potential for enzymatic acrylamide mitigation in a range of food products using asparaginase from Aspergillus oryzae. J. Agric. Food Chem. 57, 4168-4176.

Karamitros, C.S., Yashchenok, A.M., Möhwald, H., Skirtach, A.G., Konrad, M., 2013. Preserving catalytic activity and enhancing biochemical stability of the therapeutic enzyme asparaginase by biocompatible multilayered polyelectrolyte microcapsules. Biomacromolecules 14, 4398-4406.

Krishnakumar, T., Visvanathan, R., 2014. Acrylamide in food products: a review. J. Food Process. Technol. 5, 5-7.

Kukurová, K., Morales, F.J., Bednáriková, A., Ciesarová, Z., 2009. Effect of L-asparaginase on acrylamide mitigation in a fried-dough pastry model. Mol. Nutr. Food Res. 53, $1532-1539$.

Mahajan, R.V., Saran, S., Saxena, R.K., Srivastava, K., 2013. A rapid, efficient and sen sitive plate assay for detection and screening of L-asparaginase-producing microorganisms. FEMS Microbiol. Lett. 341, 122-126.

Marchettini, N., Focardi, S., Guarnieri, M., Guerranti, C., Perra, G., 2013. Determination of acrylamide in local and commercial cultivar of potatoes from biological farm. Food Chem. 136, 1426-1428.

Mari, M., Martini, C., Guidarelli, M., Neri, F., 2012. Postharvest biocontrol of Monilinia laxa, Monilinia fructicola and Monilinia fructigena on stone fruit by two Aureobasidium pullulans strains. Biol. Control 60, 132-140.

Martin, F.L., Ames, J.M., 2001. Formation of strecker aldehydes and pyrazines in a fried potato model system. J. Agric. Food Chem. 49, 3885-3892.

Medeiros Vinci, R., Mestdagh, F., De Meulenaer, B., 2012. Acrylamide formation in fried potato products - present and future, a critical review on mitigation strategies. Food Chem. 133, 1138-1154.

Mestdagh, F., Maertens, J., Cucu, T., Delporte, K., Van Peteghem, C., De Meulenaer, B., 2008. Impact of additives to lower the formation of acrylamide in a potato model system through pH reduction and other mechanisms. Food Chem. 107, 26-31.

Muso Cachumba, J.J., Fernandes, F.A., Guilherme, A., Dias Peres, F., Pereira Brumano, L., Dos Santos, J.C., Da Silva, S.S., 2016. Current applications and different approaches for microbial L-asparaginase production. Braz. J. Microbiol. 47, 77-85.

Muttucumaru, N., Powers, S.J., Elmore, J.S., Mottram, D.S., Halford, N.G., 2013. Effects of nitrogen and sulfur fertilization on free amino acids, sugars and acrylamide forming potential in potato. J. Agric. Food Chem. 61, 6734-6742.

Muttucumaru, N., Keys, A., Parry, M.A.J., Powers, S.J., Halford, N.G., 2014. Photosynthetic assimilation of $14 \mathrm{C}$ into amino acids in potato (Solanum tuberosum) and asparagine in the tubers. Planta 239, 161-170.

Muttucumaru, N., Powers, S.J., Elmore, J.S., Dodson, A., Briddon, A., Mottram, D.S., Halford, N.G., 2017. Acrylamide-forming potential of potatoes grown at different locations, and the ratio of free asparagine to reducing sugars at which free asparagine becomes a limiting factor for acrylamide formation. Food Chem. 220, 76-86.

Narta, U.K., Kanwar, S.S., Azmi, W., 2007. Pharmacological and clinical evaluation of Lasparaginase in the treatment of leukemia. Crit. Rev. Oncol. Hematol. 61, 208-221.

Pedreschi, F., Moyano, P., Kaack, K., Granby, K., 2005a. Color changes and acrylamide formation in fried potato slices. Food Res. Int. 38, 1-9.

Pedreschi, F., Mery, D., Mendoza, J., Aguilera, M., 2005b. Classification of potato chips using pattern recognition. J. Food Sci. 69, 264-270.

Pedreschi, F., Kaack, K., Granby, K., 2008. The effect of asparaginase on acrylamide formation in French fries. Food Chem. 109, 386-392.

Pedreschi, F., Mariotti, S., Granby, K., Risum, J., 2011. Acrylamide reduction in potato chips by using commercial asparaginase in combination with conventional blanching. LWT Food Sci. Technol. 44, 1473-1476.

Samir, A., Rehab, F., Mohsen, A., Wafaa, M., 2013. Impacts of pre-treatments on the acrylamide formation and organoleptic evaluation of fried potato chips. Am. J. Biochem. Biotechnol. 9, 90-101.

Saxena, R.K., Sinha, U., 1981. L-asparaginase and glutaminase activities in the culture filtrates of Aspergillus nidulans. Curr. Sci. 50, 218-219.

Shepherd, L.V.T., Bradshaw, J.E., Dale, M.F.B., McNicol, J.W., Pont, S.D.A., Mottram, D.S., Davies, H.V., 2010. Variation in acrylamide producing potential in potato: segregation of the trait in a breeding population. Food Chem. 123, 568-573.

Shi, R.Y., Mu, Q., Jiang, Z., Yang, S., 2017. Biochemical characterization of a novel Lasparaginase from Paenibacillus barengoltzii being suitable for acrylamide reduction in potato chips and mooncakes. Int. J. Biol. Macromol. 96, 93-99.

Soler, M.F., Pedreira, V.A., Longo, F.F., 2015. BB 25. Seleção de leveduras produtoras de L-asparaginase em meios sólido e líquido: uma comparação de diferentes metodologias de screening. J. Basic Appl. Pharm. Sci. 36.

Steffe, J.F., 1996. Rheological Methods in Food Process Engineering. 2. Freeman, East Lansing, pp. 1996.

Vimal, A., Kumar, A., 2017. In vitro screening and in silico validation revealed key microbes for higher production of significant therapeutic enzyme L-asparaginase. Enzym. Microb. Technol. 98, 9-17.

Zhou, W., Wang, M., Chen, J., Zhang, R., 2015. The effect of biological (yeast) treatment conditions on acrylamide formation in deep-fried potatoes. Food Sci. Biotechnol. 24, 561-566. 